\title{
Assessment of Primary Patency of the Tibial Vessels After Below the Knee Angioplasty Using Long Peripheral Balloons and Its Effect on Limb Salvage in Comparison to Using Short Balloons for Tibial Angioplasty in Previous Literature
}

\author{
Mohamed Abd El-Monem Abd El-Salam Rizk, MD; Wafi Fouad Salib, MD, \\ Ramy Mikhael Nageeb MD.
}

\author{
Vascular Surgery Department, General Surgery Department, \\ Ain Shams University
}

\begin{abstract}
Aim: To assess the primary patency of the tibial vessels after using long dilatating balloon catheters in below the knee angioplasty in patients with critical limb ischemia, and its effect on limb salvage rates. These results were compared with previous literature results of treating tibial lesions using short balloon catheters.
\end{abstract}

Patients \& methods: Twenty (20) patients with critical lower limb ischemia essentially attending the vascular out-patient clinic and the emergency department of Ain Shams University Hospitals from December 2012 till December 2014 were included in the study. Patients were treated by long balloon catheter and the primary patency of this procedure, and its effect on limb salvage were assessed.

Results: The technical success rate was 95\%, while primary patency rate after one year was $75 \%$ for patients treated by long balloon catheters for multi-segmental long tibial lesions in below the knee angioplasty. Limb salvage rate was $90 \%$ after one year. Comparison with results from previous literature using short balloons in the treatment of tibial lesions revealed no significant difference as regard technical success rate, primary patency rate or limb salvage rate.

Conclusion: Infrapopliteal angioplasty with a long balloon was feasible, with encouraging midterm outcome, in the treatment of severe limb ischemia. The advantage of long balloons is that it can easily treat complex long lesions with a single balloon covering complicated anatomy of the most of the lesion area, resulting in better arterial remodeling, also, decreased procedural time and decreased radiation exposure.

Key words: Below-the-knee lesion, critical limb ischemia, endovascular treatment.

\section{Introduction:}

Peripheral arterial disease $(\mathrm{PAD})$ is a major world-wide health problem affecting $12 \%-14 \%$ of the general population, and its prevalence increases with age, affecting as many as $20 \%$ of patients older than age 75 years. Several significant risk factors contribute to the development and progress of PAD including diabetes mellitus, hypertension, hyperlipidemia \& smoking. ${ }^{1}$ Atherosclerosis develops at a younger age in patients with diabetes and progresses rapidly.
Moreover; atherosclerosis affects more distal vessels in patients with diabetes. The profunda femoris, popliteal and tibial arteries are more frequently affected, while the aorta and iliac arteries are minimally narrowed. ${ }^{2}$ Chronic critical lower limb ischemia develops when the arterial blood flow is severely reduced to maintain the necessary requirement of normal tissues metabolism. It can be manifested clinically as rest pain, non-healing wounds or tissue loss (necrosis or gangrene). ${ }^{3}$

Tibial angioplasty has acceptable rates of 
limb salvage in patients with CLI considered to be at high risk for surgery, despite high recurrence rates. The procedure has low morbidity and mortality with lower cost compared with open revascularization. Aggressive angioplasty should be an option to patients who otherwise would face primary amputation. ${ }^{4}$

Infra-popliteal percutaneous transluminal angioplasty (PTA) with new dedicated belowthe-knee (BTK), long tapered balloon ( $>15$ $\mathrm{cm}$ ) in patients with critical limb ischemia (CLI) is feasible, safe and associated with favorable clinical results at both acute and mid-term follow-up. ${ }^{5}$

\section{Patients and methods:}

Twenty (20) patients with critical lower limb ischemia were enrolled in the study. Patients included in the study were essentially attending the vascular out-patient clinic and the emergency department of Ain Shams University Hospitals from December 2012 till December 2014. Patients were treated by long balloon catheter and the primary patency of this procedure was assessed and its effect on limb salvage.

The inclusion criteria of these patients were:

1. All patients aging $>35$ years, presenting with manifestations of critical limb ischemia which is defined as patients presenting with ischemic rest pain and tissue loss in the form of non healing ulcers or gangrene.

2. The diseased segment of the arterial tree of the lower limbs is at the level of the infrapopliteal arterial system (whether single or multiple lesions).

3. The diseased arterial segment may be occlusion( long $\leq 5 \mathrm{~cm}$ ), stenosis(long $\leq 5$ $\mathrm{cm}$, significant $>50 \%$ or tight $>75 \%$ ) or both occlusion and stenosis.

4. Patients unfit or refusing surgical infrapopliteal reconstruction.

The exclusion criteria were:

1. Patients presenting with acute lower limb ischemia.

2. Patients refusing to be included in the study.
3. Patients with associated suprapopliteal arterial diseases.

4. Patients with chronic renal impairment (not on hemodialysis)

Every patient was subjected to:

1. History taking: In the form of: (1) Personal history including special habits specially smoking history; (2) Complaint: With special attention to onset, course, and duration of the complain; (3) History of present illness

2. Clinical examination: Including general and local examination with recording of the ankle/brachial index of the affected side

3. Laboratory investigation: With special attention to kidney functions.

4. Duplex Scanning and or CT angiography

5. All patients were given Clopidogrel (Plavix) $150 \mathrm{mg} 6$ hours before the procedure.

Procedure:

1. The procedure was done under local infiltration anesthesia with antegrade puncture of the common femoral artery of the affected site while the patient was in the supine position.

2. Seldinger technique was used with introduction of a 6 F (Prelude ${ }^{\circledR}$, MeritMedical) sheath. Diagnostic angiogram was done to select the area for intervention using non ionic contrast media, evaluation of the lesion was done again to be sure that it still matches the criteria for intervention.

3. A $0.018 \mathrm{~J}$ shaped guide wire $\left(\right.$ Terumo $^{\circledR}$, Terumo corporation) was manipulated to cross the lesion as much as possible distal to the lesion, this negotiation with the lesion was done by a combination of $4 \mathrm{~F}$ or $5 \mathrm{~F}$ guiding catheter(Performa ${ }^{\circledR}$, MeritMedical).

4. After crossing the lesion, the balloon was introduced. Balloons were from 2-4 mm in diameter with length ranging from 150-300 $\mathrm{mm}$ according to length of the lesions. The length of the balloon extends over the entire length of the lesion. The balloon catheter was advanced into position over the guide wire using fluoroscopy with the aid of "road map". The balloon was slowly inflated by diluted 


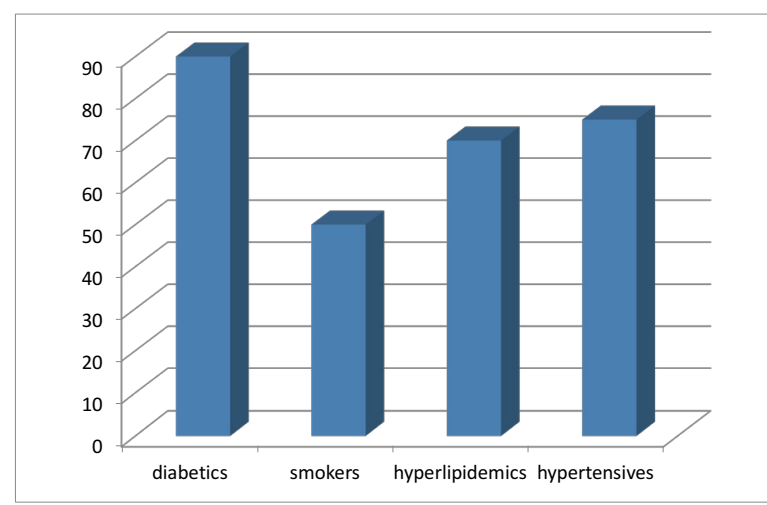

Figure (1): Risk factor assessment of the study group.
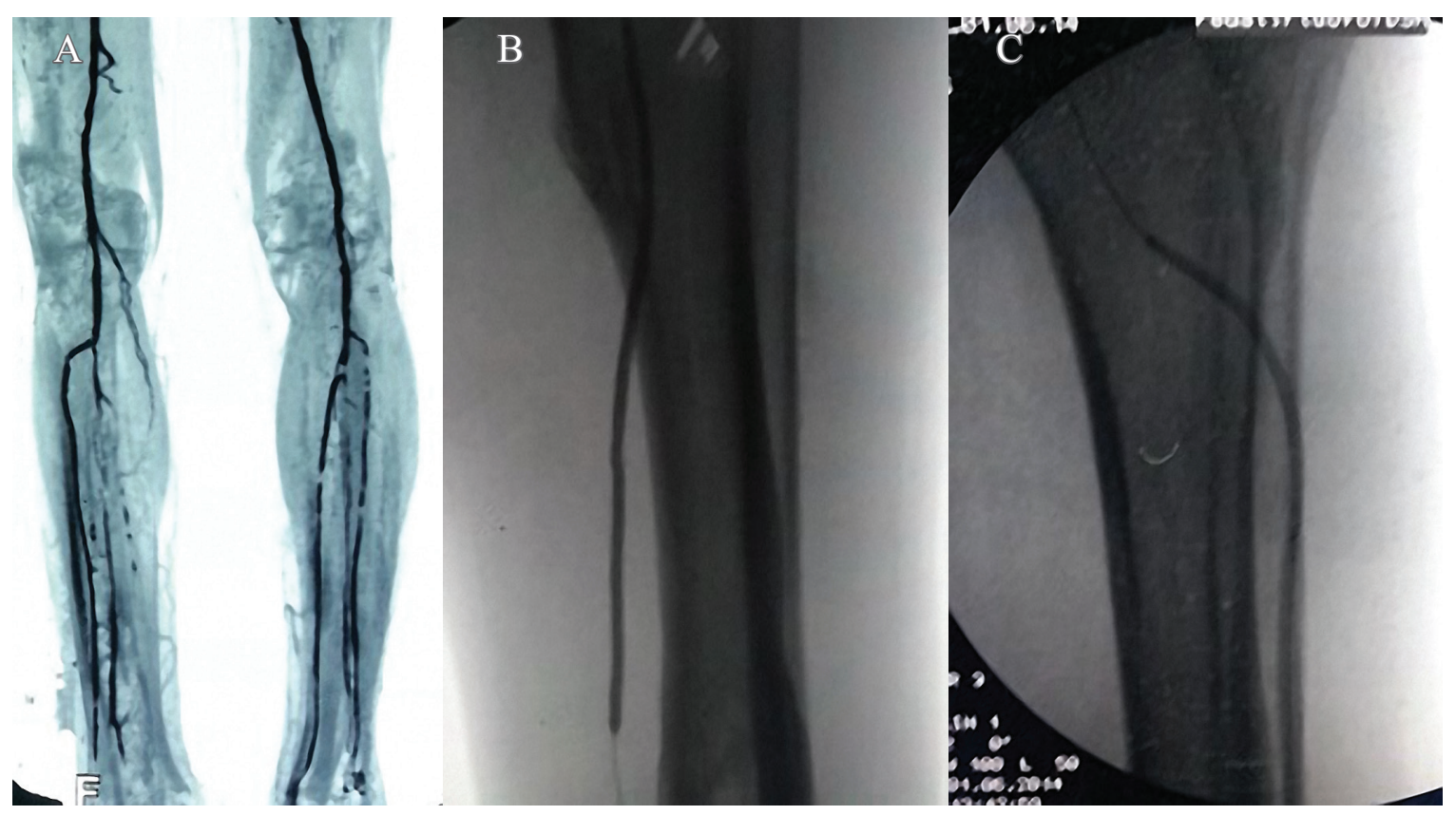

Figure (3): A: A CT angiography showing a multisegmental lesions involving the Anterior tibial, and posterior tibial vessels in a patient with left foot infected ulcer in need of urgent depridement. B: Dilatation of the posterior tibial artery using $3 \times 200 \mathrm{~mm}$ balloon. C: Dilatation of the anterior tibial artery using $3 \times 200 \mathrm{~mm}$ balloon.

Table (1): Age distribution of the study group.

\begin{tabular}{|l|l|l|}
\hline Age group & No. & $\%$ \\
\hline $45-55$ years & 3 & $15 \%$ \\
\hline $56-66$ years & 9 & $45 \%$ \\
\hline $67-80$ years & 8 & $40 \%$ \\
\hline
\end{tabular}

Table (2): Co-morbidities of the study group.

\begin{tabular}{|l|l|l|l|}
\hline \multicolumn{2}{|l|}{} & \multicolumn{1}{|c|}{ No. } & \multicolumn{1}{c|}{$\%$} \\
\hline Cardiac(CAD) & 6 & $30 \%$ \\
\hline \multirow{2}{*}{$\begin{array}{l}\text { Previous } \\
\text { amputation }\end{array}$} & Minor & 3 & $15 \%$ \\
\cline { 2 - 4 } & Major & 2 & $10 \%$ \\
\hline \multicolumn{2}{|l|}{ Cerebrovascular } & 3 & $15 \%$ \\
\hline
\end{tabular}


Table (3): Overall of limb salvage.

\begin{tabular}{|l|l|l|l|}
\hline \multicolumn{1}{|c|}{ Outcome $=\mathbf{2 0}$} & \multicolumn{1}{|c|}{ No. } & \multicolumn{1}{c|}{$\%$} & Total \\
\hline Free of amputation & 7 & $35 \%$ & \multirow{2}{*}{$90 \%$} \\
\cline { 1 - 3 } Minor amputation & 11 & $55 \%$ & \\
\hline Major amputation & 2 & $10 \%$ & $10 \%$ \\
\hline
\end{tabular}

Table (4): Results from previous studies showing initial success rate, primary patency and limb salvage rate using short balloons for treating infrainguinal lesions

\begin{tabular}{|l|l|l|l|l|l|}
\hline \multicolumn{1}{|c|}{ Study } & $\begin{array}{c}\text { No. Of } \\
\text { PTs }\end{array}$ & $\begin{array}{c}\text { Maximum length } \\
\text { of balloon(mm) }\end{array}$ & $\begin{array}{c}\text { Initial } \\
\text { success rate }\end{array}$ & $\begin{array}{c}\text { Primary } \\
\text { patency rate }\end{array}$ & $\begin{array}{c}\text { Limb } \\
\text { salvage rate }\end{array}$ \\
\hline Conrade et al 2009.6 & 144 & $\leq 3 \times 100$ & $95 \%$ & $70 \%$ & $86 \%$ \\
\hline Bosiers et al 2006.7 & 443 & $\leq 3 \times 100$ & $85 \%$ & $74 \%$ & $96 \%$ \\
\hline Dorros et al 2001.8 & 235 & $\leq 3 \times 80$ & $94 \%$ & $75 \%$ & $91 \%$ \\
\hline Iida et al 2013.9 & 314 & $\begin{array}{l}3 \times 100 \\
3 \times 120\end{array}$ & $93 \%$ & $74 \%$ & $80 \%$ \\
\hline Peregrin et al 2010.10 & 1268 & $3) \times 20$ to100) & $89 \%$ & $73 \%$ & $80 \%$ \\
\hline Total $(\mathrm{X} \pm \mathrm{SD})$ & & & $91.2 \%$ & $73.2 \%$ & $86.6 \%$ \\
\hline
\end{tabular}

Table (5): Comparing the technical success rate, primary patency rate, and limb salvage rate between our study and the mean values of previous literature.

\begin{tabular}{|l|l|l|l|l|}
\hline \multicolumn{1}{|c|}{ Outcome } & \multicolumn{1}{|c|}{$\begin{array}{c}\text { Our } \\
\text { study }\end{array}$} & $\begin{array}{c}\text { Mean values of } \\
\text { previous literatures }\end{array}$ & $\begin{array}{c}\mathbf{X}^{\mathbf{2}} \\
\text {-test }\end{array}$ & P-value \\
\hline Initial technical success rate & $95 \%$ & $91.2 \%$ & $0.078^{*}$ & $>0.05$ \\
\hline Primary patency rate & $75 \%$ & $73.2 \%$ & $0.063^{*}$ & $>0.05$ \\
\hline Limb salvage rate & $90 \%$ & $86.6 \%$ & $0.069^{*}$ & $>0.05$ \\
\hline
\end{tabular}

contrast solution under fluoroscopy, using an inflation device.

5. Inflation pressure ranging from $6-10$ atmospheres. Inflations were generally held for 30-90 seconds and were repeated once if there was evidence of persistent or residual stenosis after the initial inflation.

6. Completion angiography was done for evaluation of angioplasty results. Technical success was defined as improvement of luminal diameter of more than $50 \%$ or less than $30 \%$ residual stenosis.

7. Manual compression of the puncture site: Immediately after removal of the sheath for 15 to 20 minutes (it was done immediately after the procedure).

8. In the immediate post procedure period, the patient was followed up for pedal pulsations, temperature, color of skin, motor power, capillary refilling, together with measurement of Ankle/Brachial index(ABI). If the patient was in need of urgent debridement it was done in the setting of the angioplasty, otherwise debridement was postponed till the $3^{\text {rd }}$ day postprocedural.

9. All patients were maintained on Clopidogrel $75 \mathrm{mg}$ once daily, together with acetyl salicylic acid $100 \mathrm{mg}$ and a lipid lowering agent for at least 6 months.

10. Follow up was done weekly for 4 weeks postoperatively then followed up every month for 4 months, then every couple of months for one year, which was in the form of clinical examination to assess improvement of symptoms, ankle/brachial index to compare with the preprocedural one, 
and duplex scanning.

\section{Results:}

This study was conducted on 20 patients From December 2012 till June 2014. Patients included in the study were essentially attending the vascular out-patient clinic and emergency department at Ain Shams University Hospitals treated by tibial angioplasty with long balloon catheter.

The patients included in the study were 15 males versus 5 females with a percentage of $75 \%$ and $25 \%$ respectively. The mean age of patients was $64 \pm 11.1$ years (ranging from 45 to 80 years). The distribution of the age groups of the patients are shown in Table (1):

Assessment of risk factors for the studied group together with the associated comorbidities are shown in Figure (1) and Table (2) respectively.

Of the studied group, only one patient had rest pain on the left side lower limb of more than two weeks not responding to analgesia. Nine of the studied patients (45\%) had minor tissue loss or gangrene, (15\%) had major tissue loss.

The site and the degree of the lesions was found to be, one $(5 \%)$ of our patients had lesions only in the anterior tibial artery, Two $(10 \%)$ affect only posterior tibial artery and seventeen $(85 \%)$ patients with a combined infrapopliteal arterial lesions, twenty eight $(53.8 \%)$ of the lesions were stenosis of arterial segments $(28.8 \%$ with significant stenosis less than $75 \%$ luminal reduction and $25 \%$ with tight stenosis more than $75 \%$ luminal reduction) and twenty four patients (46.2\%) of the lesions were arterial occlusions (13.5\% with short occlusion less than or equale $2 \mathrm{~cm}$ in length and $32.7 \%$ with long occlusion more than $2 \mathrm{~cm}$ length).

The technical success rate was $95 \%$ as the procedure succeeded in nineteen patients and failed in one patient(severely calcified long occlusions) who underwent below knee amputation, follow up was done by duplex examination and assessment of ABI, after six months the primary patency rate was $85 \%$ as another patient underwent below knee amputation and recurrence of rest pain (restenosis) had occurred in another patient, after 12 months of follow up we recorded two cases with restenosis and decrease of ABI so the primary patency rate after 12 months was $75 \%$, as shown in Figure (2).

$55 \%$ of our patients (11) underwent minor amputations (1 tarso-metatarsal, 2 middle toes, 2 the 2 nd and 3rd toes, 1 little toe, 2 the lateral 2 toes, 1 the 2 nd toe and 2 big toe), $35 \%$ (7) of our patients treated were free of amputation. While only two patients in this study underwent major amputations (below knee amputation).

The comparison between our study and previous studies that used short balloon catheters $(\leq 12 \mathrm{~cm}$ in length) in treatment of tibial aterial lesions, is shown in Table (4).

The mean results of those 5 studies were compared with the results of our study and the P-value was calculated by Fisher-exact test, and the result was found to be non significant as shown in Table (5).

\section{Discussion:}

This study is concerned with the primary patency of Angioplasty with long balloon catheters for long multi-segmental tibial lesions in patients with critical lower ischemia, and its effect on quality of life and limb salvage \& comparing its results to previous studies had used short balloon catheters.

Follow up of the patients was done by clinical examination and assessment of improvement of patient complaint (rest pain), and healing of ulcers, full pulse examination of the lower limb arterial system for all patients with recording of the ankle brachial pressure index, limb salvage rate, Lower limb arterial duplex.

Follow up over 12 months revealed patency rate of $(75 \%)$, and limb salvage among overall patients (90\%).

The immediate technical success in our series for PTA was 95\%, 55\% underwent minor amputation.

A study by Jue Wang et al., showed immediate technical success rate of $92.5 \%$, limb salvage rate of $94 \%$ and patency rate of (59\%) over 12 months follow up, 11\% underwent minor amputation. ${ }^{11}$ 
In another study by Gandini et al., showed that $93.5 \%$ with immediate technical success rate, $100 \%$ limb salvage rate and patency rate of (77.4\%) over 12 months follow up, 16.1\% underwent minor amputation. ${ }^{5}$

In a retrospective study, patients experiencing CLI had endovascular treatment including Below The Knee (BTK) Percutaneous Transluminal Angioplasty. Limb Salvage Rate (LSR) for patients who had a successful procedure was $87 \%$ at 1 year and 3 years. Two-thirds of patients had total vessel dilatation with improved LSR at 1 year and 3 years $89 \% .^{12}$

After 12 months follow up of our patients, the data was collected and analysed statestically and then compared with previous literatures concerned with treatment of infrapopliteal arterial lesions by shorter balloon catheters angioplasty.

Conrade et al performed a retrospective review of below-knee percutaneous interventions in 144 patients with CLI. Patients were treated with angioplasty by balloon length not exceedes $10 \mathrm{~cm}$. The initial success rate was $95 \%$, the overall primary patency rate at 1 year was $70 \%$ and The overall limb salvage rate for 1 year was $86 \%{ }^{6}$

Bosiers et al., performed angioplasty between September 2002 and June 2005, 443 patients (355 Rutherford category 4, 82 category 5, 6 category 6) underwent intervention for 681 BTK lesions. Patients were treated with angioplasty by balloon length not exceeding $10 \mathrm{~cm}$. The initial success rate was $85 \%$, the overall primary patency rate at 1 year was $74 \%$ and The overall limb salvage rate for 1 year was $96 \%{ }^{7}$

Dorros et al., performed a prospective, nonrandomized, consecutive series of tibioperoneal vessel angioplasty for 235 patients. Patients were treated with angioplasty by balloon length not exceeding $8 \mathrm{~cm}$. The initial success rate was $94 \%$, the overall primary patency rate at 1 year was $75 \%$ and The overall limb salvage rate for 1 year was $91 \% .8$

In Iida et al., A prospective multicenter study was conducted to evaluate the clinical outcomes of 314 Japanese critical limb ischemia patients. Patients were enrolled from December 2009 to July 2011 and were followed-up for 12 months. Patients were treated with angioplasty by balloon length $10 \& 12 \mathrm{~cm}$. The initial success rate was $93 \%$, the overall primary patency rate at 1 year was $74 \%$ and the overall limb salvage rate for 1 year was $80 \% .^{9}$

From 1999 to 2007 Peregrin et al., performed infrapopliteal angioplasty as a primary procedure in a total of 1445 lower limbs of 1268 patients. Patients were treated with angioplasty by ballon length ranged from 2 to $10 \mathrm{~cm}$. The initial success rate was $89 \%$, the overall primary patency rate at 1 year was $73 \%$ and The overall limb salvage rate for 1 year was $80 \% .{ }^{10}$

\section{Conclusion:}

Endovascular treatment of below the knee lesions is a valid and robust therapy for critical limb ischemia, with excellent results (either long or short balloon catheters as there is no significant difference in their results). We anticipate that endovascular intervention will become the primary treatment for below the knee lesions in CLI patients, with 1-year primary patency, limb salvage, and survival rates that compare favorably with published surgical data.

Infrapopliteal angioplasty using long balloon catherters can be performed safely with favorable results in patients, with accepted primary patency rates in comparison to using short balloons.

Advantages of long balloon catheters includes decreased procedural time, decreased radiation exposure, less vessel occlusion time and risk of thrombosis, Less risk of emboli resulting from advancing or withdrawing winged balloons across diseased segments and less risk of dissection as dilation is from normal segment distally to normal segment proximally

Infrapopliteal angioplasty with a long balloon was feasible, with encouraging midterm outcome, in the treatment of severe limb ischemia. The advantage of long balloons is most clearly evident in cases of 
complex distal revascularization such as those involving the pedal arch. In these cases, the diseased arch can be easily treated with a single balloon covering complicated anatomy of the most of the lesion area, resulting in better arterial remodeling, also, decreased procedural time and decreased radiation exposure. The limited sample size in this study does not enable however a definitive appraisal of the clinical role of this type of balloon catheters so Further studies are necessary to evaluate long-term outcome.

\section{Reference:}

1- Misra S: EverFlex stent in SFA peripheral artery disease (Ever done or moving on?). $J$ Vasc Interv Radiol 2012; 23: 1322-1323.

2- Brown AL, Juergens JL: Arteriosclerosis and atherosclerosis. Quoted from: Allen EV, et al. Peripheral vascular disease. Philadelphia: Saunders 2005; 57-66.

3- Varu VN, Hogg ME, Kibbe MR: Critical limb ischemia. J Vasc Surg 2010; 51: 230-241.

4- Werneck CC, Lindsay TF: Tibial angioplasty for limb salvage in high-risk patients and cost analysis, Ann Vasc Surg 2009; 23(5): 554-559.

5- Gandini R, Volpi T, Pampana E, Uccioli L, Versaci F, Simonetti G: Applicability and clinical results of percutaneous transluminal angioplasty with a novel, long, conically shaped balloon dedicated for below-the knee interventions. J Cardiovasc Surg (Torino) 2009; 50(3): 365-371.

6- 6. Conrad MF, Kang J, Cambria RP, Brewster DC, Watkins MT, Kwolek CJ, LaMuraglia GM: Infrapopliteal balloon angioplasty for the treatment of chronic occlusive disease. $J$ Vasc Surg 2009; 50: 799-805.

7- Bosiers M, Hart JP, Deloose K, Verbist
J, Peeters P: Endovascular therapy as the primary approach for limb salvage in patients with critical limb ischemia: Experience with 443 infrapopliteal procedures. Vascular 2006; 14: 63-69.

8- Dorros G, Jaff MR, Dorros AM, Mathiak LM, He T: Tibioperoneal (Outflow lesion) angioplasty can be used as primary treatment in 235 patients with critical limb ischemia five-year follow-up. Circulation 2001; 104 : 2057-2062.

9- Iida O, Nakamura M, Yamauchi Y, Fukunaga M, Yokoi Y, Yokoi H, Soga Y, Zen K, Suematsu N, Inoue N, Suzuki K, Hirano K, Shintani Y, Miyashita Y, Urasawa K, Kitano I, Tsuchiya T, Kawamoto K, Yamaoka T, Uesugi M, Shinke T, Oba Y, Ohura N, Uematsu M, Takahara M, Hamasaki T, Nanto S: OLIVE Investigators: Endovascular treatment for infrainguinal vessels in patients with critical limb ischemia OLIVE registry, a prospective, multicenter study in Japan with 12-month follow-up. Circ Cardiovasc Interv 2013; 6: 68-76.

10- Peregrin JH,KoznarB,Kovac J,Lastovickova J, Novotny J, Vedlich D, Skibova J: PTA of infrapopliteal arteries: Long-term clinical follow-up and analysis of factors influencing clinical outcome. Cardiovasc Intervent Radiol 2010; 33: 720-725

11- Wang J, Zhu YQ, Zhao JG, Wang JB, Cheng YS, Li MH, Wang W, Zhang PL, Du ZY: Infrapopliteal angioplasty with a long overthe-wire (OTW) balloon in the treatment of severe limb ischemia in diabetic patients: A retrospective study. Acta Radiol 2009; 50(4): 360-367.

12- Odink H, Van den Berg A, Winkens B: Technical and clinical long-term results of infrapopliteal percutaneous transluminal angioplasty for critical limb ischemia. $J$ Vasc Interv Radiol 2012; 23: 461-467. 


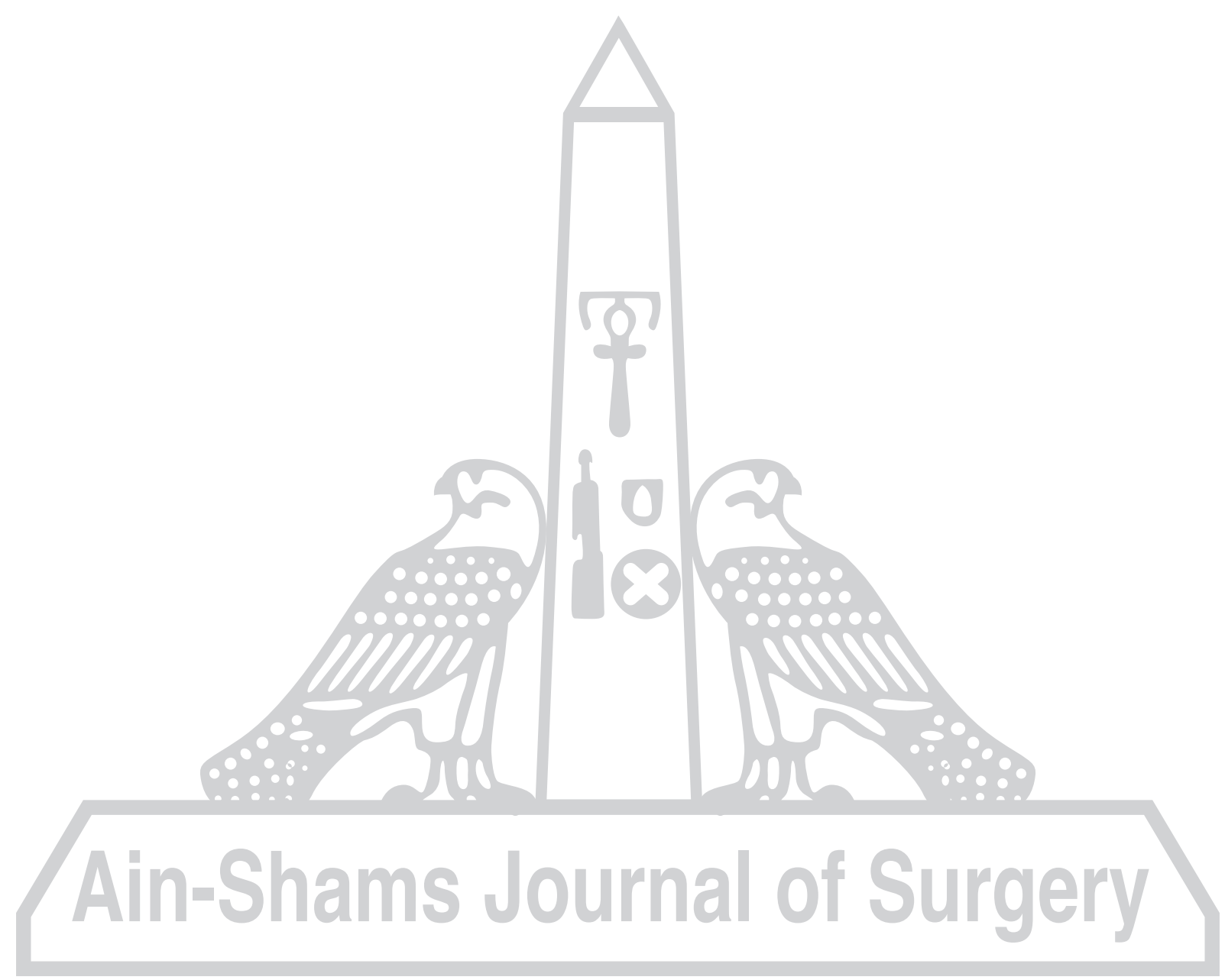

